\title{
A comparative analysis of the metaphase chromosomes of Aedes excrucians, Ae. behningi, Ae. intudens and Ae. punctor mosquitoes species (Diptera: Culicidae) in Tomsk region
}

\author{
Alekseeva S.S. ${ }^{1,2 *}$, Andreeva Yu.V. ${ }^{1}$, Wasserlauf I.E. ${ }^{1}$, Sibataev A.K. ${ }^{1}$, Stegniy V.N. ${ }^{1}$ \\ ${ }^{1}$ Tomsk State University, Tomsk, Russia \\ ${ }^{2}$ Laboratory of Evolutionary Genomics of Insects, the Federal Research Center Institute of Cytology and Genetics, Siberian \\ Branch of the Russian Academy of Sciences, Novosibirsk, Russia \\ *e-mail: sveta.alexx@mail.ru
}

Key words: mosquitos, Aedes, metaphase chromosomes, rDNA

Motivation and Aim: Mosquitos from the genus Aedes are vectors of many human and animal diseases such as yellow fever, Zika fever, dengue fever, chikungunya and other. The Aedes species mosquitoes are spread all over the world. Some of the species inhabit local native areas but other invade in large territories outside of their native range. Thus, precise identification of the Aedes species is of medical importance. Many species in the Aedes genus is difficult to identify. The complex methods are required for precise identification of some Aedes species. The analysis of metaphase chromosomes in the Aedes species can be an additional tool for species identification that can be used in combination of other methods.

Methods and Algorithms: A comparative analyses of the metaphase chromosomes of 4 Aedes species (Ae. excrucians, Ae. behningi, Ae. intudens, Ae. punctor) were performed. Lacto-aceto-orcein chromosome stain and imagJ program were used for measuring of the chromosome length. C- and DAPI stains visualized centromeric regions and some patterns in intercalary areas. Fluorescent in situ hybridization (FISH) was used to analyze the location of rDNA genes.

Results: Based on morphological data these 4 species belong to two different groups in Aedes genus. Ae. excrucians, Ae. behningi belong to Cantans group and Ae. intudens, Ae. punctor are part of Communis group. Analysis of rDNA localization indicate that rDNA is located in chromosome 1 in Cantans group mosquitoes but in contrast, in chromosome 2 in Communis group mosquitoes. The chromosome length are different for all analyzed species of Aedes genus (Ae. excrucians, A. behningi, Ae. intudens, and Ae. punctor). Calculation of centromeric index reveals that all three pairs of chromosomes are centromeric. Cand DAPI stains show different size and brightness of centromeric regions among the species.

Conclusion: The chromosome analysis of metaphase chromosomes of Aedes species can be used as a chromosome-based tool for identification of Ae. excrucians, Ae. behningi, Ae.intudens, Ae. punctor mosquito species in a combination with other identification methods.

Acknowledgements: Mosquitos collections and chromosome preparations was funded by RFBR, project number № 19-34-90044 to VNS. The data analysis and FISH was supported by the Russian Science Foundation Grant No. 19-14-00130 to Maria V Sharakhova. 